\title{
Новинки аналитического оборудования компании Shimadzu
}

Д. А. Фармаковский, В.Н. Цупрева, к.х. Н., Shimadzu

УДК 543.07 smo_vts@shimadzu.ru

\begin{abstract}
Корпорация Shimadzu, один из лидеров аналитического приборостроения, постоянно работает над расширением и совершенствованием модельного ряда оборудования. Новые модели приборов отвечают растущим потребностям в высокой эффективности работы, точности и надежности получаемых результатов и удобства эксплуатации. В статье представлены новинки оборудования для масс-спектрометрии и молекулярной спектроскопии - наиболее востребованных на сегодняшний день классов аналитических инструментов.
\end{abstract}

\section{МАСС-СПЕКТРОМЕТРИЯ}

В 2018 году линейка приборов компании Shimadzu для масс-спектрометрии пополнилась двумя новыми моделями: жидкостным гибридным масс-спектрометром высокого разрешения LCMS-9030 (рис. 1) и компактным времяпролетным масс-спектрометром с ионизацией MALDI - MALDI-8020 (рис. 2).

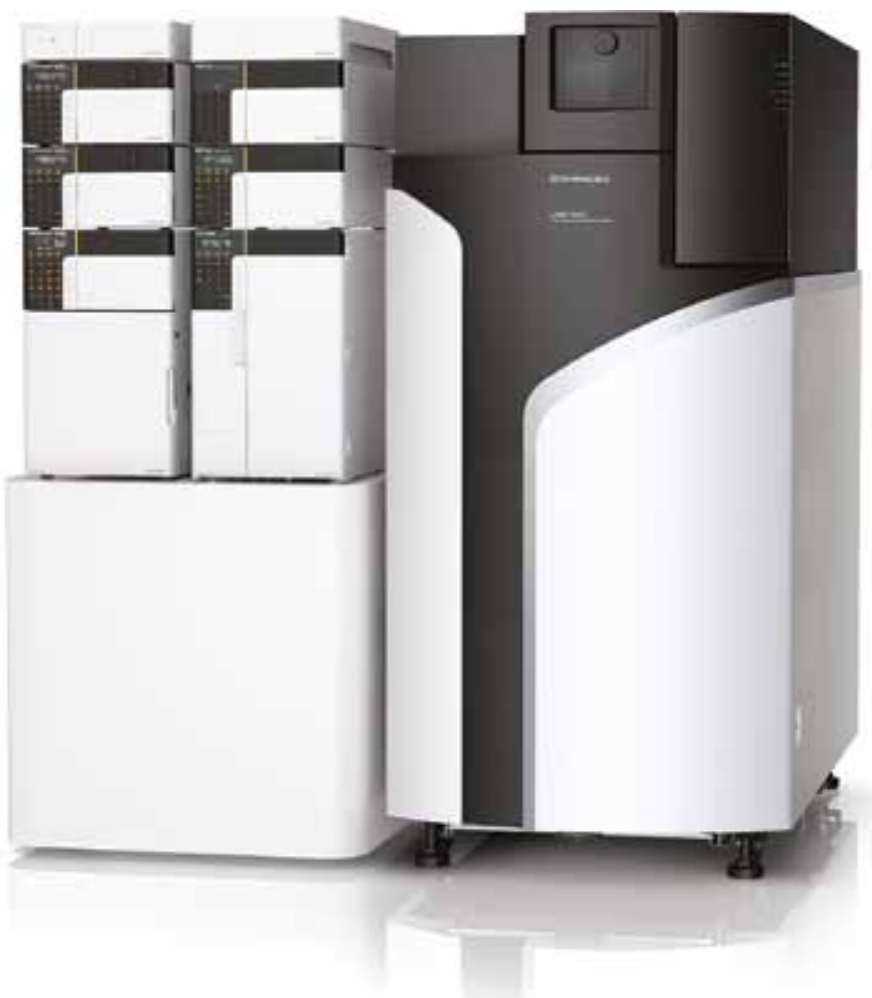

Puс. 1. Жидкостный гибридный масс-спектрометр высокого разрешения LCMS-9030
LCMS-9030 - первый гибридный масс-спектрометр Shimadzu, в котором реализована традиционная комбинация: квадрупольный анализатор масс-и времяпролетная труба с рефлектроном. В конструкции прибора использованы уже апробированные технологии сверхбыстрой массспектрометрии, например, источники ионизации Plugand-Play с горячим газом, система ионной оптики Qarray, быстродействующие квадруполь и ячейка соударительной диссоциации, а также совершенно новые решения, специально разработанные для максимальной эффективности работы времяпролетного масс-анализатора.

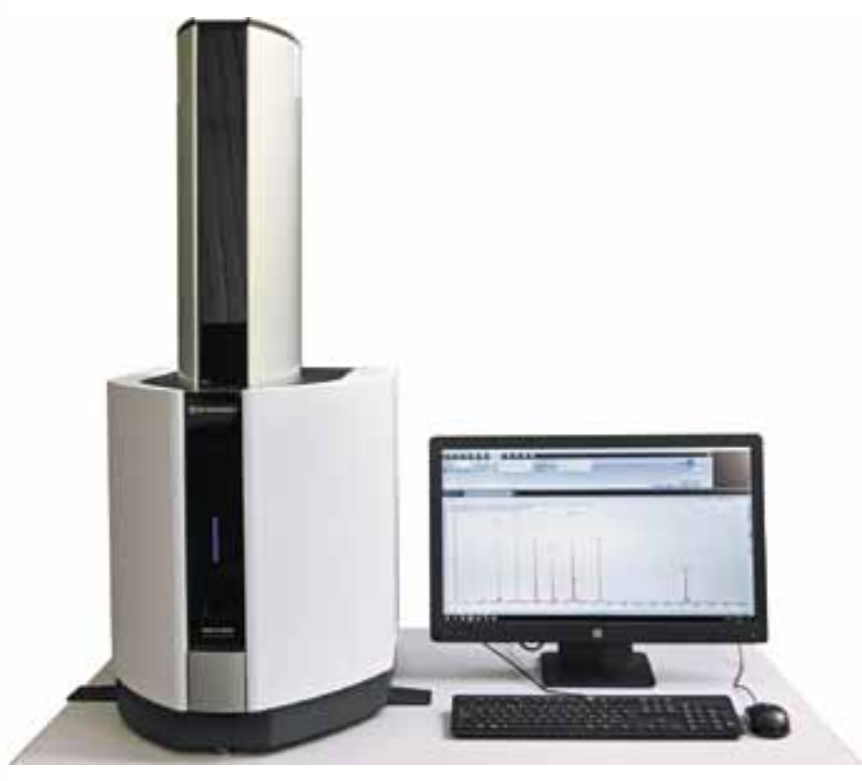

Puc. 2. Компактный времяпролетный масс-спектрометр с ионизацией MALDI - MALDI-8020 
В первую очередь это технология активного температурного контроля времяпролетной трубы UFFlightTube, которая существенно повышает стабильность определения масс, снижая тем самым потребность в периодической калибровке масс-спектрометра. Это, с одной стороны, упрощает повседневную работу с прибором, а с другой - увеличивает производительность лаборатории. B LCMS-9030 установлен рефлектрон новой конструкции iRefTOF, формирующий практически идеальное отражающее электростатическое поле, благодаря которому отсутствуют потери в чувствительности и разрешении.

Высокий уровень чувствительности анализа обеспечивают технологии UFaccumulation, UFgrating и новая конструкция детектора с воронкообразной формой микроканалов. Первая технология позволяет эффективно аккумулировать пакеты ионов в ячейке соударительной диссоциации, а благодаря запатентованному решетчатому электроду UFgrating с максимальной механической прочностью стало возможным использование существенно более высокого по сравнению с традиционными конструкциями выталкивающего напряжения для максимального ускорения ионов.

В дополнение к установленному по умолчанию источнику ионизации электроспреем (ESI) LCMS-9030 может быть оснащен источником химической ионизации при атмосферном давлении (APCI) и комбинированным источником ионизации DUIS. Последний представляет собой эффективную комбинацию возможностей химической ионизации и ионизации электроспреем. Конструкция источников ионизации такова, что при их замене пользователю не придется отключать какие-либо провода и подводящие трубки. Достаточно просто разблокировать источник и поднять его вверх. На источниках ионизации всех типов (ESI, APCI, DUIS) может быть установлена система ввода калибровочного стандарта. При этом используется отдельный ионизационный капилляр, который функционирует независимо от основного ионизационного капилляра. Благодаря этому калибровочные стандарты можно вводить в масс-спектрометр в любое время, когда это необходимо, без замены линии подачи растворов и без риска контаминации основной аналитической линии.

Настольный линейный MALDI-TOF масс-спектрометр MALDI-8020 в первую очередь ориентирован на работу в лабораториях контроля качества современных биотехнологических производств, где может использоваться для высокопроизводительного анализа белков, пептидов, синтетических полимеров или олигонуклеотидов. Он оснащен сверхбыстрым твердотельным УФ-лазером с длиной волны излучения 355 нм и частотой импульсов до 200 Гц, системой скоростной загрузки образцов и отличается пониженным уровнем шума (<55 дБ).
Длительную бесперебойную работу MALDI-8020 обеспечивает широкоапертурная ионная оптика, которая минимизирует риск загрязнения источника ионизации. В дополнение к этому прибор имеет функцию автоматической очистки элементов ионной оптики TrueClean тем же самым лазером, которым ионизируется образец.

Программное обеспечение MALDISolutions включает базу данных Microsoft SQL для безопасного хранения результатов анализов и характеристик работы массспектрометра. Программное обеспечение поддерживает гибкое регулирование параметров доступа пользователей к настройкам прибора и данным и полностью соответствует требованиям 21 CFR part 11.

\section{СПЕКТРОФОТОМЕТРИЯ}

Весной 2018 года компания Shimadzu представила новый УФ-Вид-спектрофотометр UV-1900, который работает в широком спектральном диапазоне от 190 до 1100 нм (рис. 3). В режиме ультрабыстрого сканирования спектрофотометр позволяет проводить измерения со скоростью 29000 нм/мин (для измерений в видимом диапазоне спектра требуется около трех секунд). Уникальные характеристики прибора полностью соответствуют философии компании Excellence in Science. Повторные измерения, исследование кинетики быстрых реакций могут быть проведены за максимально короткое время.

Двулучевая оптическая схема с монохроматором Черни-Тернера и запатентованной LO-RAY-LIGH дифракционной решеткой гарантирует низкий уровень рассеянного излучения (0,5\% при 198 нм (KCl)) и один из самых больших диапазонов линейности. UV-1900 отличают высокие разрешение и чувствительность, а хорошая фотометрическая воспроизводимость (менее $\pm 0,0002 \mathrm{Abs}$ (при 0,5 и 1 Abs)) обеспечивает точные количественные измерения даже очень разбавленных образцов. Этому способствует низкий уровень шума <0,00005 Abs (700 нм) и стабильность нулевой линии <0,0003 Abs/час (700 нм). Ширина спектральной щели спектрофотометра UV-1900 составляет 1 нм, что соответствует требованиям к прибору, прописанным

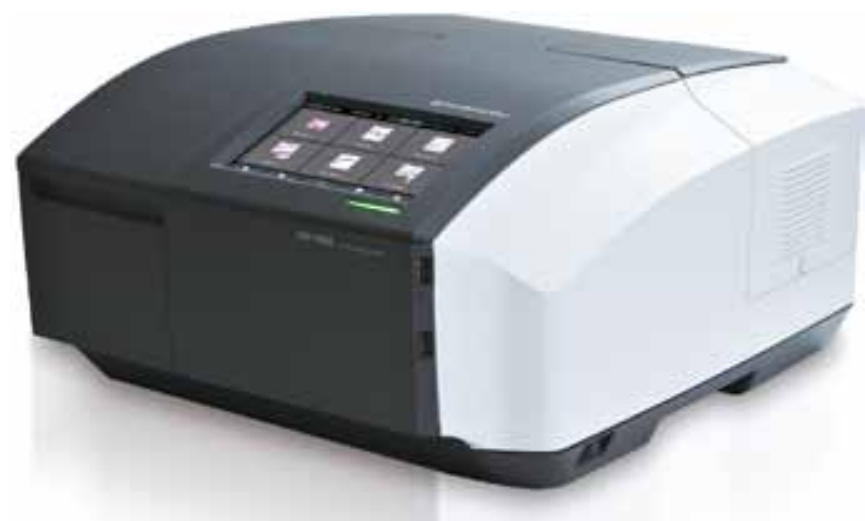

Puc. 3. Спектрофотометр UV-1900 
в Фармакопеях разных стран. Помимо этого, в сочетании с программным обеспечением LabSolutions DB / CS соблюдаются рекомендации FDA 21 CFR Часть 11 и PIC/S GMP, а также осуществляется единое управление данными, полученными с разных приборов, включая хроматографы и ИК-фурье-спектрометры.

Управление UV-1900 возможно как с помощью встроенного программного обеспечения, так и посредством пО нового поколения LabSolutions UV-Vis. UV-1900 имеет большой сенсорный дисплей с крупными значками, который обеспечивает интуитивное понимание встроенного пО и позволяет пользователям быстро ознакомиться с операциями. Кроме того, ЖК-дисплей спектрофотометра UV-1900 расположен под оптимальным углом, а для удобства управления прилагается стилус. Благодаря удобной навигации все этапы анализа осуществляются легко и быстро. ПО LabSolutions UV-Vis - программное обеспечение для пользователей из разных сегментов промышленности. Помимо функций измерения и анализа, доступна возможность оценки результатов измерения (критерий соответствия / несоответствия). Простой экспорт данных в текстовый или табличный формат повышает эффективность работы.

Сочетание спектрофотометра UV-1900 с программным обеспечением LabSolutions DB / CS позволяет интегрировать прибор в единую систему управления данными в соответствии с требованиями различных руководств и положений, касающихся электронных записей и подписей.

Таким образом, представленные модели оборудования характеризуются хорошей производительностью, высокими чувствительностью и разрешением, соответствуют требованиям и рекомендациям нормативной документации.

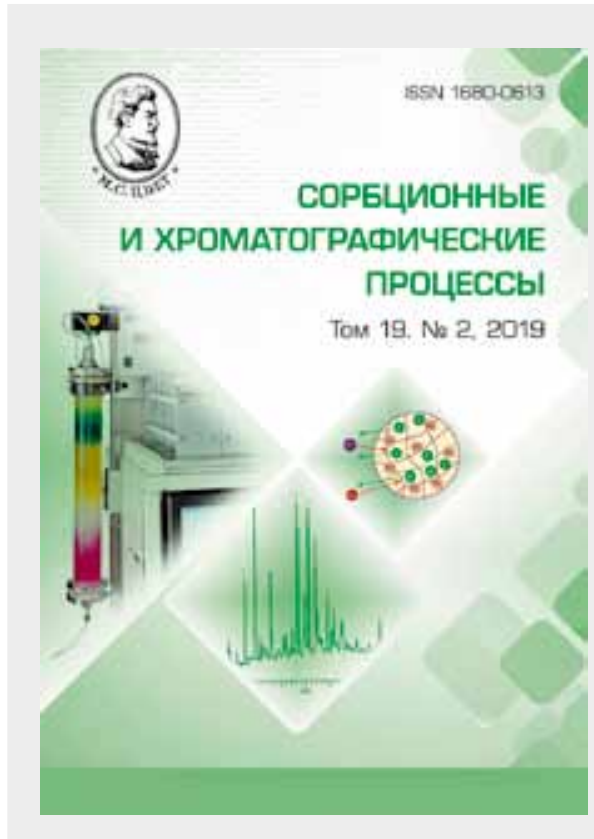

Вышел в свет очередной номер журнала "Сорбционные и хроматографические процессы" 2019, т. 19, № 2, ISSN1680-0613

Журнал издается с 2000 года с периодичностью 6 раз в год и является преемником сборника "Теория и практика сорбционных процессов". Учредитель: Воронежский государственный университет

Ульянов А. В., Полунина И.А., Полунин К. Е., БурякА. К. Хроматографическое разделение продуктов взаимодействия 1,1-диметилгидразина с изотиоцианатами
Просунцова Д.С., Ананьева И.А.,

Плодухин А. Ю., Белоглазкина Е. К., Шпигун О.А. Синтез и исследование сорбента для ВЭЖХ на основе сополимера стирола и дивинилбензола, модифицированного наночастицами золота

Доронин А. Г., Дейнека В. И., Дейнека Л.А., Тохтарь В. К., Селеменев В. Ф.

Использование ВЭЖХ при поиске нетрадиционных источников антоцианов. Антоцианы листьев краснолистных форм клена остролистного и клена веерного японского

Шилько Е.А., Милевская В. В., Темердашев 3.А., Киселева Н. В. Сорбционные характеристики сорбентов для твердофазной экстракции фенольных соединений из экстрактов лекарственных растений

Платонов И.А., Платонов Вл. И., Платонов Вал. И., Ворон С. В. Разработка методики анализа летучих органических соединений в почве с использованием портативного хроматографа на основе микрофлюидных систем

Котова Д. Л., Сокрюкина А. И., Крысанова Т.А. Равновесная сорбция метиленового голубого на клиноптилолите

Дробь А.А., Васияров Г.Г., Титова Е. В., Староверов С. М., Якуба Ю.Ф., Гугучкина Т. И. Оптимизация методов ВЭЖХ контроля антоцианового состава вин и виноматериалов
Шапошник В.А. Сопряженный перенос ионов и теплоты через катионообменную мембрану при электродиализе малорастворимых электролитов

Дампилова Б. В., Зонхоева э. Л. Исследование природных лантансодержащих цеолитов методом растровой электронной микроскопии

Нистратов А. В., Скарюкин А. С., Клушин В. Н. Получение и исследование пористой структуры минерально-углеродных адсорбентов на основе силикагеля и полимерных отходов

Васильева Е. В., Воронюк И. В., Елисеева Т. В. Особенности сорбционного извлечения метаналя волокнистым ионообменником ФИБАН А-5W

Соловей В.Н., Самонин В. В., Спиридонова Е.А., Подвязников М.Л. Композиционные сорбирующие изделия на основе силикагеля для осушки газовых сред

Guskov V.Yu., Shaihitdinova Yu. F., Zilberg R.A., Kraikin V.A., Maistrenko V. N. Intermolecular interactions between polyarylenephthalides surface and organic compounds of different nature by inverse gas chromatography data

Панарин В. Ю., Баум Е.А., Ланин С. Н. История развития представлений об адсорбции в конце 18 и 19 веке

Рыбакова Е. В. Пионеры синтеза ионообменных материалов. 120 лет со дня рождения Александра Борисовича Даванкова (1899-1971) 


\section{SHIMADZU}

Excellence in Science

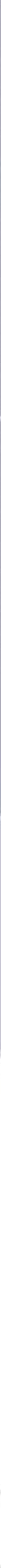

\section{Новинки оборудования Shimadzu}

- Новая УВЭЖХ серия с искусственным интеллектом Nexera LC-40

- Жидкостный гибридный масс-спектрометр LCMS-9030

- Компактный линейный MALDI-TOF масс-спектрометр MALDI-8020

- Газовые квадрупольные хроматомассспектрометры серии NX: GCMS-QP2020 NX GCMS-TQ8040 NX GCMS-TQ8050 NX

- УФ-Вид спектрофотометр UV-1900

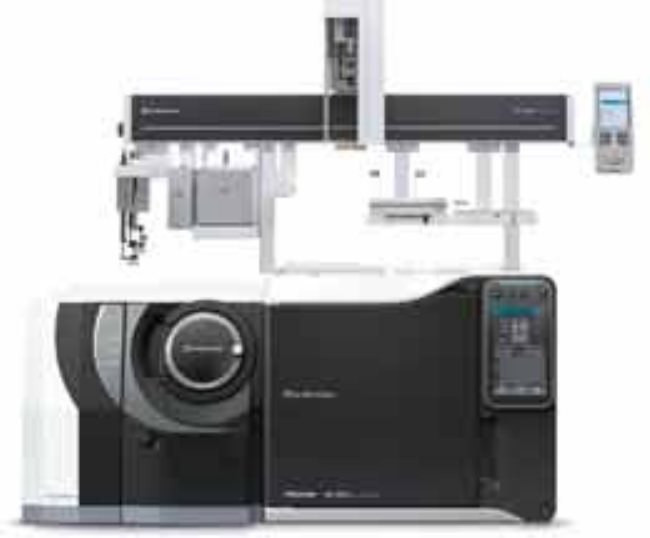

